\title{
Flash Spark Plasma Sintering (FSPS) of pure $\mathrm{ZrB}_{2}$
}

\author{
Salvatore Grasso ${ }^{\mathrm{a}, \mathrm{b}}$, Theo Saunders ${ }^{\mathrm{a}, \mathrm{b}}$, Harshit Porwal ${ }^{\mathrm{a}, \mathrm{b}}$, Omar Cedillos Barraza ${ }^{\mathrm{c}}$, Daniel \\ Doni Jayaseelan $^{c \#}$, William Edward Lee ${ }^{c, \#}$, Mike Reece $^{\mathrm{a}, \mathrm{b}^{* \# \#}}$ \\ ${ }^{a}$ School of Engineering and Material Science, Queen Mary University of London, London, E1 4NS, UK \\ ${ }^{b}$ Nanoforce Technology Limited, London, E1 4NS, UK \\ ${ }^{c}$ Centre for Advanced Structural Ceramics (CASC) and Department of Materials, Imperial College London, \\ South Kensington Campus, London SW7 2AZ, UK \\ * E-mail: m.j.reece@qmul.ac.uk \\ \# member Of the American Ceramic Society
}

\begin{abstract}
Pure $\mathrm{ZrB}_{2}$ powder was Flash sintered in an SPS furnace (FSPS). The samples were densified up to $95.0 \%$ in 35 seconds under an applied pressure of $16 \mathrm{MPa}$. Compared to Conventional SPS (CSPS), the newly developed FSPS technique resulted in an unprecedented energy and time savings of about $95 \%$ and $98 \%$ respectively. $\mathrm{ZrB}_{2}$ monoliths obtained by CSPS and FSPS were compared with respect to microstructures, densification behaviour and grain growth. The developed methodology might find application to a wide range of highly conductive ceramics as refractory borides and carbides.
\end{abstract}

\section{Introduction}

There has been a growing interest in Flash Sintering (FS) since the recent publication of Cologna et al. ${ }^{1}$, especially in the field of ceramics where there has been extensive work carried out on zirconia ${ }^{2,3}$ and other ceramics such as $\mathrm{SnO}_{2}{ }^{4}, \mathrm{TiO}_{2}{ }^{5}$ and $\mathrm{SiC}^{6}$. There has also been some work to explain the rapid densification of zirconia ceramics. Modelling ${ }^{7}$ and experimental analysis confirmed ${ }^{8}$ a localized overheating of the samples due to the Joule effect. It has been reported that the sample temperature might exceed the nominal furnace temperature by more than $1000^{\circ} \mathrm{C}$.

The FS sample shape is typically bone like ${ }^{1}$, which maximizes the power dissipation. However this shape does not have any practical application. During FS experiments, the quantity of processed material is very limited. For example Cologna et al. ${ }^{1}$ employed a peak power dissipation of $60 \mathrm{~W}$ for 0.6 grams of TZ3Y. Typically electrodes are made of platinum; which makes the whole process less commercially attractive for large scale manufacturing. Samples must be preheated before the FS can occur. This work aims to employ SPS as a tool for producing flash sintered materials in bulk quantities (tens of grams) and so avoid the intrinsic limitations of existing FS.

Zirconium diboride is a refractory compound $\left(\mathrm{T}_{\mathrm{m}} \sim 3246{ }^{\circ} \mathrm{C}\right)$ that is widely used for ultra-high temperature applications. Due to its strong covalent bonding, only a few techniques have been demonstrated to be effective in densifying it in the absence of sintering aids. In particular Zapata-Solvas et al. succeeded in manufacturing near fully dense materials by using SPS ${ }^{9}$. The typical SPS conditions for densifying $\mathrm{ZrB}_{2}$ above $90 \%$ includes a heating rate of $100{ }^{\circ} \mathrm{C} / \mathrm{min}$ and pressure of the order of $50 \mathrm{MPa}$ at temperatures between 1900 and $2100{ }^{\circ} \mathrm{C}$.

Most of the materials flash sintered so far exhibit limited electrical conductivity and thus they require electric fields exceeding $100 \mathrm{~V} / \mathrm{cm}$. On the contrary, $\mathrm{ZrB}_{2}$ due to its high electrical conductivity requires much lower processing voltages, thus resulting in more controllable and more homogeneous sintering process. Hence, SPS, which employs high current density and low voltages $<10 \mathrm{~V}^{10}$ is an ideal technique for densifying highly electrically conductive as $\mathrm{ZrB}_{2}$ ceramics in a flash. The proposed methodology has not been reported before in the literature.

\section{Experimental procedure}


$\mathrm{ZrB}_{2}$ grade B with average particle size of $2.4 \mu \mathrm{m}$ supplied by Starck (Germany) containing impurities of $\mathrm{C} 0.13$; O 0.8; $\mathrm{N} \mathrm{0.21;} \mathrm{Hf} 1.77$, wt $\%$ was used as starting material. All the experiments were carried out using an SPS furnace (FCT HPD 25; FCT Systeme GmbH, Rauenstein, Germany) under vacuum (5 Pa).

This powder was densified to make a solid sample. In a typical sintering experiment, $8 \mathrm{~g}$ of $\mathrm{ZrB}_{2}$ powder was poured into a $20 \mathrm{~mm}$ diameter graphite die. To perform the FSPS sintering experiments, the $\mathrm{ZrB}_{2}$ powder was partially sintered under $16 \mathrm{MPa}$ at $1600{ }^{\circ} \mathrm{C}$ for 20 minutes. At this stage the density was $63.6 \%$ and strong enough to be processed by FSPS. To perform FSPS the sample was pressed between two graphite punches of $3 \mathrm{~cm}$ diameter. The temperature was probed by the top pyrometer focused on the inner graphite wall of the pressing punch at a distance $4 \mathrm{~mm}$ from the sample. In the FSPS configuration, no graphite mould was employed, so the current passed entirely across the sample, which is a common feature with FS. In order to minimize the heat loss by radiation from the sample, a graphite felt was wrapped around the $\mathrm{ZrB}_{2}$ during sintering. In FSPS experiments, a constant uniaxial pressure of $16 \mathrm{MPa}$ was applied. The samples were discharged under a peak power of about $25 \mathrm{~kW}$ for $0,10,15,25$ and 35 seconds. The power was rapidly reduced after the discharge and it was maintained for a few seconds. For comparison, the samples were also sintered using a CSPS configuration in the temperature range of $1600-2100^{\circ} \mathrm{C}$ under a uniaxial pressure of $16 \mathrm{MPa}$, with a dwelling time of 20 minutes. Since the density did not increased by reheating the samples up to $1600 \mathrm{C}$, the CSPS were sintered in a single step

The density was measured according to ASTM C373-88. The theoretical density of $\mathrm{ZrB}_{2}$ is 6.119 $\mathrm{g} / \mathrm{cm}^{3}{ }^{9}$. The effect of the impurities in the starting powder was accounted in the measurement. Due to the presence of unreacted carbon in the FSPS samples, the lower limit of the density was assumed to be $5.90(0.2 \%$ wt graphitic carbon as in the starting powder) while the upper limit was 6.11 .

Samples were characterized by SEM (FEI, Inspect F, Hillsboro, USA) and Raman (Renishaw inVia Raman microscope, Gloucestershire, UK) at a laser power of $12.5 \mathrm{~mW}$ using $514 \mathrm{~nm}$ argon laser.

\section{Results and discussion}

As confirmed by experiments carried out to densify samples in CSPS configuration, the CSPS cycle takes about 40-45 minutes, which is much longer if compared to the 25-35 seconds needed in the FSPS experiments. To densify a $2 \mathrm{~cm}$ diameter sample ( 8 grams) at $2100{ }^{\circ} \mathrm{C}$ for 20 minutes by CSPS about $4 \mathrm{kWh}$ of energy was needed, while for densifying the same sample by FSPS only $0.2 \mathrm{kWh}$ was used. This corresponded to an energy saving of $95 \%$. The room temperature reported value for electrical conductivity of dense $\mathrm{ZrB}_{2}$ is of $9.710^{6} \mathrm{~S} / \mathrm{m}^{11}$. It is difficult to draw comparison between FS and FSPS for materials such as $\mathrm{SnO}_{2}{ }^{4}, \mathrm{TiO}_{2}{ }^{5}$, and $\mathrm{SiC}^{6}$ as they have lower room temperature electrical conductivities in the range of $10^{2}-10^{4} \mathrm{~S} / \mathrm{m}$. The benefits of FSPS compared to conventional FS include: (1) using non-expensive graphite electrodes instead of Platinum, (2) production of samples of large volume (10 times bigger $)^{1}$, (3) not requiring voltages higher than $10 \mathrm{~V}$, which might result in inhomogeneous microstructures as confirmed by experimental observation in Ref. ${ }^{12}$, and no need of preheat treatment of the samples in order to initiate the FS. All the combined advantages make FSPS attractive route for densifying a wide range of conductive materials, at high rate, with inherent energy saving.

Figure 1 shows output data generated during FSPS of a $\mathrm{ZrB}_{2}$ sample; (a) piston displacement rate, (b) power dissipation and (c) temperature. Figure 1 (a) shows that between 10 and 20 seconds there is a sudden increase in the shrinkage rate approaching $20 \mathrm{~mm} / \mathrm{min}$ and then remained constant at $10 \mathrm{~mm} / \mathrm{min}$ until final densification. For the given experimental set-up, the power dissipation (Fig. 1(b)) and current during the FSPS stabilized at about $25 \mathrm{~kW}$ and $1.53 \mathrm{kA}$ respectively. Figure 1 (c) shows the processing temperature profile, the peak temperatures reached for each sample time is highlighted. The heating rate approached $4000{ }^{\circ} \mathrm{C} / \mathrm{min}$, which is 40 time higher than in CSPS.

Figures 2 show the relative density and grain size of $\mathrm{ZrB}_{2}$ samples obtained by CSPS (Figures (a)) and FSPS Figures (b)) sintered at different temperatures and for different discharge times. In agreement with the displacement rate shown in Figure 1 (a), densification in FSPS occurred between 15 and 35 seconds, during which the density increased from 75.9 to $95.0 \%$. As shown in Figure 1(c), the peak temperature was $2198{ }^{\circ} \mathrm{C}$ after $35 \mathrm{~s}$ of discharging. In CSPS when the temperature was increased from 2000 to $2100^{\circ} \mathrm{C}$ the grain size 
sharply increased from 6 to $18.2 \mu \mathrm{m}$. Similarly, in the case of FSPS the grain growth was significant only when the processing temperature was above $2000{ }^{\circ} \mathrm{C}$; the average grain size increased from 2.6 to $11.8 \mu \mathrm{m}$ for the samples FSPSed for 25 and $35 \mathrm{~s}$.

Figure 3 shows the microstructure evolution of FSPS samples discharged for 0,15 and 35 seconds. Figure 3 (a) shows the microstructure of a predensified sample. It contains similar microstructural features to the starting powder $\left(\mathrm{D}_{10 \mathrm{vol} \%}<0.5 \mu \mathrm{m}, \mathrm{D}_{50 \mathrm{vol} \%}<2.4 \mu \mathrm{m}, \mathrm{D}_{90 \mathrm{vol} \%}<4.2 \mu \mathrm{m}\right)$ where finer particles coexist with larger ones, and an irregular grain size distribution is observed. After $25 \mathrm{~s}$ discharge the relative density reached $84.7 \%$ and mild grain growth was evident. The particle configuration is representative of second stage sintering. After $35 \mathrm{~s}$ discharge, which is representative of third stage sintering, significant grain growth occurred and the porosity became closed. Figure 3 (c) confirmed a dense microstructure, however some large voids are observed and they are indicated by arrows. Such voids are localized at the grain $\mathrm{ZrB}_{2}$ grain boundaries. High magnification images of this area are shown in Figure 3 (d); EDX point analysis revealed 71 atomic $\%$ carbon and the balance zirconium.

The presence of carbon is attributed to the starting powder. Figures 4 (a) shows the Raman spectra of $\mathrm{ZrB}_{2}$ samples sintered using CSPS and FSPS (35 sec). $\mathrm{ZrB}_{2}$ is not Raman active ${ }^{13}$.Typical D ( 1355) and G $(\sim 1580)$ peaks ${ }^{14}$ of graphitic carbon related to defects and $\mathrm{sp}^{2}$ hybridised carbon respectively, were observed in both FSPS and CSPS materials. However, their intensity, and position were different. The starting $\mathrm{ZrB}_{2}$ contains graphitic carbon (0.13 to $2 \mathrm{wt} \%$ ) which was added in excess for carbothermal reduction and it compensates for the presence of oxygen $(0.8 \mathrm{wt} \%)$ during CSPS, resulting in very weak D and G peak intensities for CSPS $\mathrm{ZrB}_{2}$.

\section{Conclusions}

This work is the first attempt to densify $\mathrm{ZrB}_{2}$ monoliths using a very rapid heating rate $\left(4000{ }^{\circ} \mathrm{C} / \mathrm{min}\right)$ and short processing time (35 seconds). Dense and crack free samples were obtained. FSPS resulted in a densification up to about $95.0 \%$ combined with unprecedented energy and time savings of about $95 \%$ and $98 \%$, respectively, when compared to CSPS. Unlike FS, FSPS might be industrially attractive since it might be easily implemented on an even larger scale and it does not requires high voltages $(<10 \mathrm{~V})$. Future work will be focused on up scaling and applicability to other electric conductive systems.

\section{Figure captions}

Figures 1. SPS data recorded during FSPS of $\mathrm{ZrB}_{2}$ discharged for $35 \mathrm{~s}$. The displacement rate (a), heating power (b) and temperature (c) are shown. In Figure (c) the peak temperature reached after discharge times of 10, 15, 25 and 35 are also shown.

Figures 2. Comparison of the relative density and grain size of samples densified by CSPS (a) and FSPS (b). In CSPS, the samples were heated and cooled at $100^{\circ} \mathrm{C} / \mathrm{min}$ and dwelled for 20 minutes. Both FSPS and CSPS the samples were sintered under a uniaxial pressure of $16 \mathrm{MPa}$

Figures 3. SEM images of $\mathrm{ZrB}_{2}$ samples. Figure (a) Shows a sample presintered at $1600{ }^{\circ} \mathrm{C}$ for 20 minutes, Figure (b) and (c,d) show the FSPS microstructure evolution after 15 and $35 \mathrm{~s}$ discharge respectively as detailed in Figure 1.

Figure 4. Raman spectra of (a) FSPS and CSPS samples.

\section{Acknowledgements}


S.G. was supported by EPSRC (EP/K008749/1, XMat). T.S. was supported by EC FP7 20072013 (ADMACOM) and by EPSRC (EP/K008749/1, XMat).

\section{References}

1. M. Cologna, B. Rashkova, and R. Raj, "Flash sintering of nanograin zirconia in $<5 \mathrm{~s}$ at $850^{\circ} \mathrm{C}, "$ Journal of the American Ceramic Society, 93[11] 3556-59 (2010).

2. J. A. Downs and V. M. Sglavo, "Electric field assisted sintering of cubic zirconia at $390^{\circ}$ C," Journal of the American Ceramic Society, 96[5] 1342-44 (2013).

3. R. Muccillo and E. N. S. Muccillo, "An experimental setup for shrinkage evaluation during electric field-assisted flash sintering: Application to yttria-stabilized zirconia," Journal of the European Ceramic Society, 33[3] 515-20 (2013).

4. R. Muccillo and E. N. S. Muccillo, "Electric field-assisted flash sintering of tin dioxide," Journal of the European Ceramic Society, 34[4] 915-23 (2014).

5. S. K. Jha and R. Raj, "The effect of electric field on sintering and electrical conductivity of Titania," Journal of the American Ceramic Society, 97[2] 527-34 (2014).

6. E. Zapata-Solvas, S. Bonilla, P. R. Wilshaw, and R. I. Todd, "Preliminary investigation of flash sintering of SiC," Journal of the European Ceramic Society, 33[13-14] 2811-16 (2013).

7. S. Grasso, Y. Sakka, N. Rendtorff, C. Hu, G. Maizza, H. Borodianska, and O. Vasylkiv, "Modeling of the temperature distribution of fla shsintered zirconia," Nippon Seramikkusu Kyokai Gakujutsu Ronbunshi/Journal of the Ceramic Society of Japan, 119[1386] 144-46 (2011).

8. J. Park and I. W. Chen, "In situ thermometry measuring temperature flashes exceeding $1,700^{\circ} \mathrm{C}$ in $8 \mathrm{~mol} \%$ Y2O3-stablized zirconia under constant-voltage heating," Journal of the American Ceramic Society, 96[3] 697-700 (2013).

9. E. Zapata-Solvas, D. D. Jayaseelan, H. T. Lin, P. Brown, and W. E. Lee, "Mechanical properties of $\mathrm{ZrB} 2$ - and $\mathrm{HfB} 2$-based ultra-high temperature ceramics fabricated by spark plasma sintering," Journal of the European Ceramic Society, 33[7] 1373-86 (2013).

10. S. Grasso, Y. Sakka, and G. Maizza, "Electric current activated/assisted sintering (ECAS): A review of patents 1906-2008," Science and Technology of Advanced Materials, 10[5] (2009).

11. M. Mallik, A. J. Kailath, K. K. Ray, and R. Mitra, "Electrical and thermophysical properties of $\mathrm{ZrB} 2$ and HfB2 based composites," Journal of the European Ceramic Society, 32[10] 2545-55 (2012).

12. M. C. Steil, D. Marinha, Y. Aman, J. R. C. Gomes, and M. Kleitz, "From conventional ac flash-sintering of YSZ to hyper-flash and double flash," Journal of the European Ceramic Society, 33[11] 2093-101 (2013).

13. A. L. Ortiz, V. Zamora, and F. Rodríguez-Rojas, "A study of the oxidation of ZrB 2 powders during high-energy ball-milling in air," Ceramics International, 38[4] 285763 (2012).

14. H. Porwal, P. Tatarko, S. Grasso, C. Hu, A. R. Boccaccini, I. Dlouhý, and M. Reece, "Toughened and machinable glass matrix composites reinforced with graphene and graphene-oxide nano platelets," Sci Technol Adv Mat, 14 (2013). 


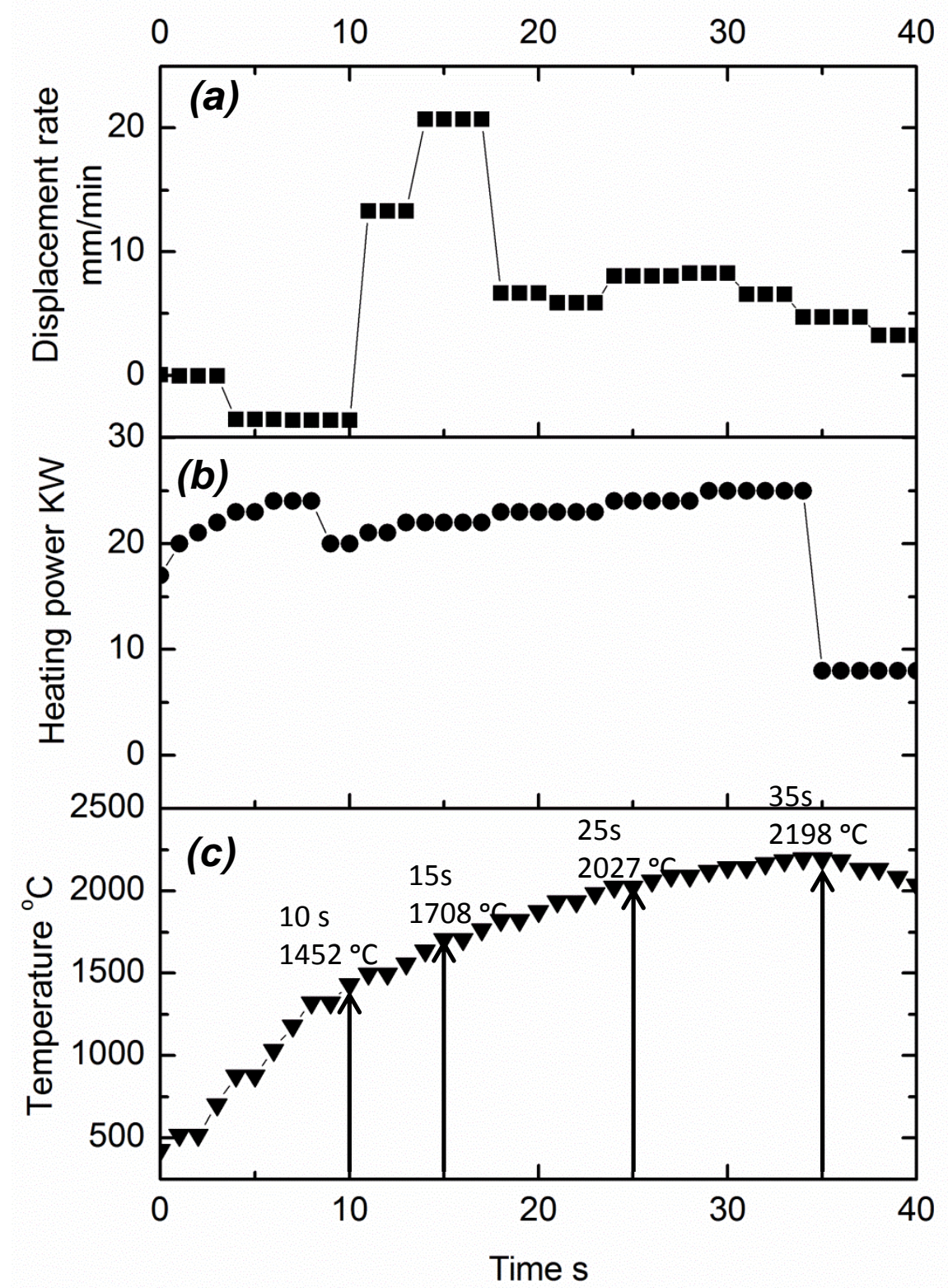



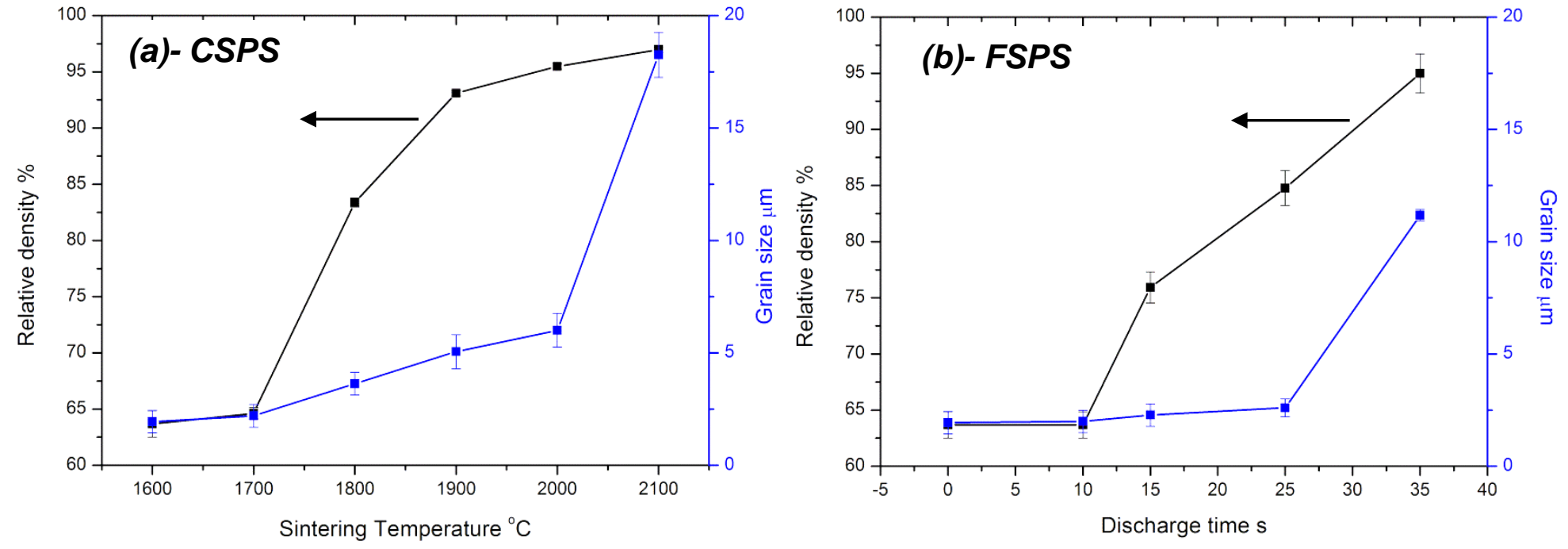

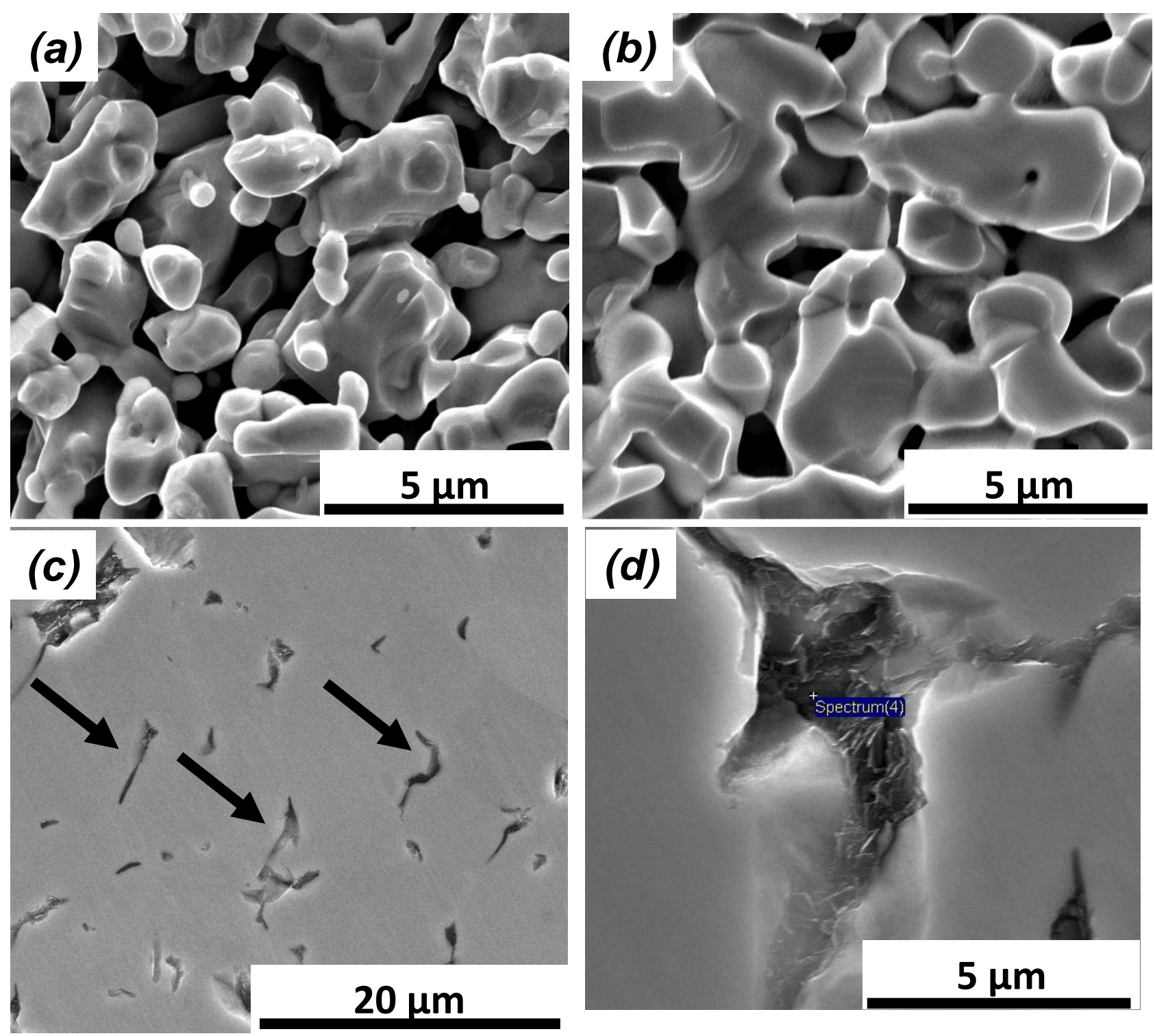


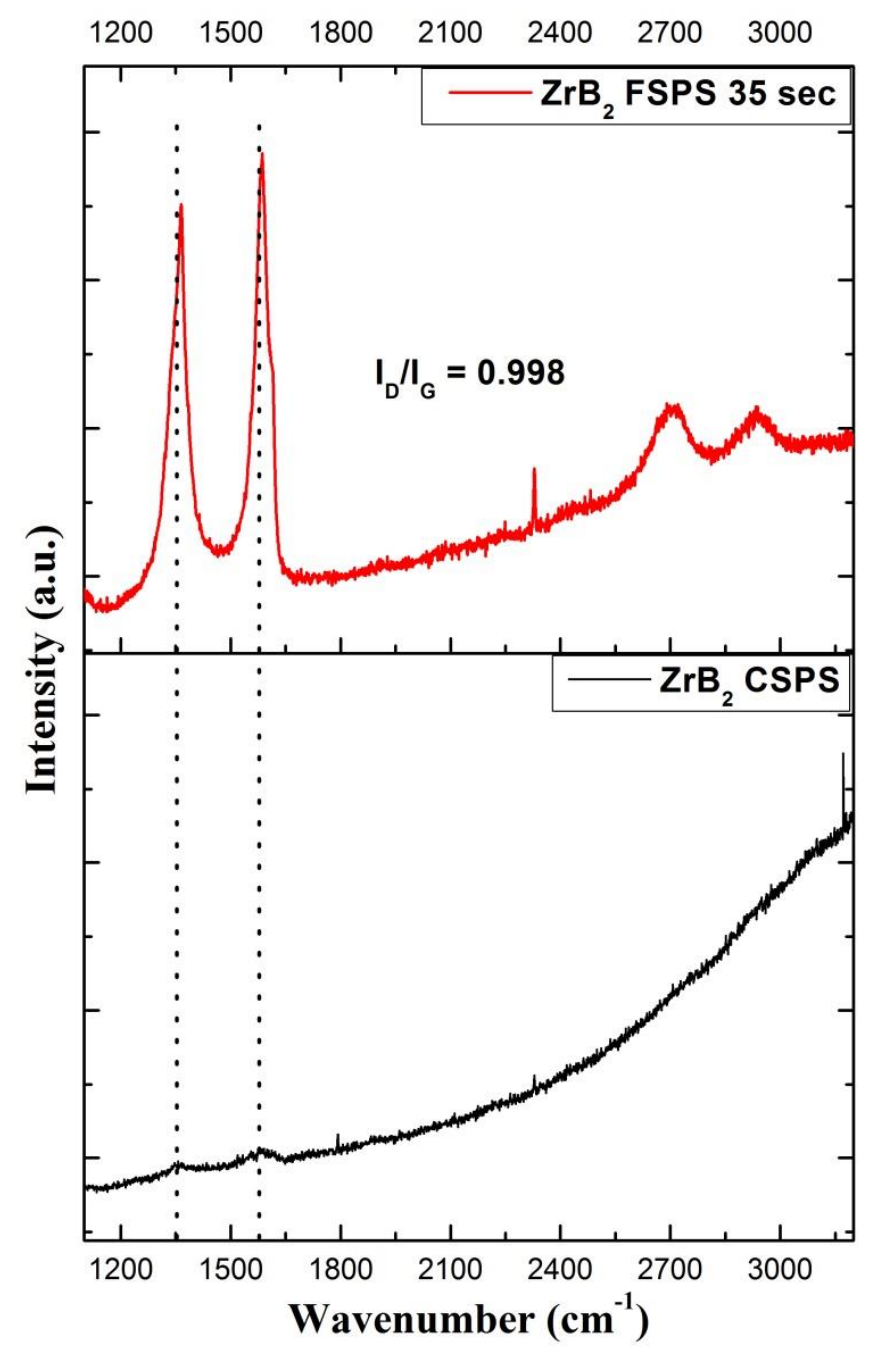

